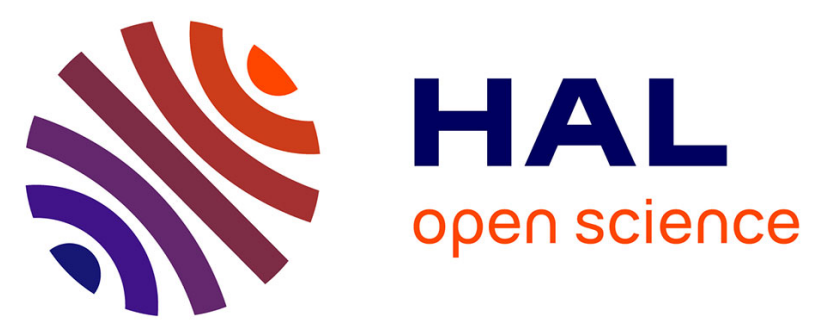

\title{
Prospective Randomized Crossover Study of a New Closed-loop Control System versus Pressure Support during Weaning from Mechanical Ventilation
}

Noémie Clavieras, Marc Wysocki, Yannaël Coisel, Fabrice Galia, Matthieu Conseil, Gerald Chanques, Boris Jung, Jean-Michel Arnal, Stefan Matecki, Nicolas Molinari, et al.

\section{To cite this version:}

Noémie Clavieras, Marc Wysocki, Yannaël Coisel, Fabrice Galia, Matthieu Conseil, et al.. Prospective Randomized Crossover Study of a New Closed-loop Control System versus Pressure Support during Weaning from Mechanical Ventilation. Anesthesiology, 2013, 119 (3), pp.631-641. 10.1097/ALN.0b013e3182952608 . hal-02544907

\section{HAL Id: hal-02544907 \\ https://hal.umontpellier.fr/hal-02544907}

Submitted on 16 Apr 2020

HAL is a multi-disciplinary open access archive for the deposit and dissemination of scientific research documents, whether they are published or not. The documents may come from teaching and research institutions in France or abroad, or from public or private research centers.
L'archive ouverte pluridisciplinaire HAL, est destinée au dépôt et à la diffusion de documents scientifiques de niveau recherche, publiés ou non, émanant des établissements d'enseignement et de recherche français ou étrangers, des laboratoires publics ou privés. 


\title{
Prospective Randomized Crossover Study of a New Closed-loop Control System versus Pressure Support during Weaning from Mechanical Ventilation
}

\author{
Noémie Clavieras, M.D., ${ }^{\star}$ Marc Wysocki, M.D.,† Yannael Coisel, M.D., ${ }^{\star}$ Fabrice Galia, Ph.D.,ł \\ Matthieu Conseil, M.D., ${ }^{\star}$ Gerald Chanques, M.D., Ph.D.,§ Boris Jung, M.D., Ph.D.,§ \\ Jean-Michel Arnal, M.D., || Stefan Matecki, M.D., Ph.D.,\# Nicolas Molinari, Ph.D., ${ }^{\star \star}$ Samir Jaber, M.D., Ph.D.††
}

\begin{abstract}
Background: Intellivent is a new full closed-loop controlled ventilation that automatically adjusts both ventilation and oxygenation parameters. The authors compared gas exchange and breathing pattern variability of Intellivent and pressure support ventilation (PSV).
\end{abstract}

* Research Fellow, Intensive Care Unit, Anesthesiology and Critical Care Department B, Saint Eloi Teaching Hospital, Montpellier, France. $\dagger$ Associate Researcher, Research Center, Sainte-Justine University Hospital, Montréal, Quebec, Canada. $\neq$ Associate Researcher Engineer, § Associate Professor of Anesthesiology and Critical Care, Intensive Care Unit, Anesthesiology and Critical Care Departmen B, Saint Eloi Teaching Hospital, Université Montpellier 1, Montpellier, France. I| Staff Physician in Critical Care, Service de réanimation polyvalente, Hôpital Sainte Musse, Toulon, France. \# Professor, Clinical Physiology Center, Arnaud de Villeneuve Teaching Hospital, Université Montpellier 1, Centre Hospitalier Universitaire Montpellier, Montpellier, France. ** Associate Professor of Statistic, Medical and Informatic Department, Lapeyronie University Hospital of Montpellier, Montpellier, France. + Professor and Chairman, Intensive Care Unit, Anesthesiology and Critical Care Department B, Saint Eloi Teaching Hospital, Université Montpellier 1, Centre Hospitalier Universitaire Montpellier, Montpellier, France.

Chanques, Arnal, Matecki, Molinari, and Jaber have no conflicts of interest. Dr. Wysocki was the director of the Medical Research Department of Hamilton Medical when the study was designed. Dr. Wysocki is co-sharing a patent on Intellivent (WO/2007/085110 and WO/2007/085108). He did not participate in the study design, data analysis, and conclusions. Support was provided solely from institu-

Address correspondence to Dr. Jaber: Intensive Care Unit, Department of Anesthesiology (DAR B), CHU de Montpellier, Hôpital Saint Eloi, 80 Avenue Augustin Fliche, 34295 Montpellier Cedex 5, France.s-jaber@chu-montpellier.fr. This article may be accessed
Methods: In a prospective, randomized, single-blind design crossover study, 14 patients were ventilated during the weaning phase, with Intellivent or PSV, for two periods of $24 \mathrm{~h}$ in a randomized order. Arterial blood gases were obtained after $1,8,16$, and $24 \mathrm{~h}$ with each mode. Ventilatory parameters were recorded continuously in a breath-by-breath basis during the two study periods. The primary endpoint was oxygenation, estimated by the calculation of the difference between the $\mathrm{PaO}_{2} / \mathrm{F}_{\mathrm{IO}}$ ratio obtained after $24 \mathrm{~h}$ of ventilation and the $\mathrm{PaO}_{2} / \mathrm{FIO}_{2}$ ratio obtained at baseline in each mode. The variability in the ventilatory parameters was also evaluated by the coefficient of variation (SD to mean ratio).

Results: There were no adverse events or safety issues requiring premature interruption of both modes. The $\mathrm{PaO}_{2} /$ $\mathrm{FIO}_{2}($ mean \pm SD) ratio improved significantly from $245 \pm 75$ at baseline to $294 \pm 123(P=0.03)$ after $24 \mathrm{~h}$ of Intellivent. The coefficient of variation of inspiratory pressure and positive end-expiratory pressure (median [interquartile range]) were significantly higher with Intellivent, 16 [11-21] and $15[7-23] \%$, compared with $6[5-7]$ and 7 [5-10]\% in PSV. Inspiratory pressure, positive end-expiratory pressure, and $\mathrm{FIO}_{2}$ changes were adjusted significantly more often with Intellivent compared with PSV.

Conclusions: Compared with PSV, Intellivent during a 24-h period improved the $\mathrm{PaO}_{2} / \mathrm{FIO}_{2}$ ratio in parallel with more variability in the ventilatory support and more changes in ventilation settings. 
$\mathbf{P}$ RESSURE support ventilation (PSV) is the most widely used assisted mode of ventilation during the weaning process, in both medical and surgical critically ill patients. ${ }^{1}$ However, PSV provides a fixed inspiratory pressure $\left(\mathrm{P}_{\text {INSP }}\right)$, regardless of the patient's ventilatory demand or gas exchange, which limits breathing pattern variability. ${ }^{2-5}$ Given the high variability in disease processes and states, the application of predefined, uniform values for ventilator parameters, such as a fixed $\mathrm{P}_{\text {INSP }}$ or tidal volume (VT), is unlikely to provide optimal assist at all times. ${ }^{6}$ In contrast, variability in the breathing pattern may be useful in improving gas exchange as suggested by previous reports in animals ${ }^{7,8}$ or recently in humans. ${ }^{2}$

New ventilatory modes can offer ventilation automatically adjusted to the patient's ventilatory demand. ${ }^{2,5,9,10}$ Studies that evaluated these modes have shown benefits on the optimization of ventilation, ${ }^{2,11}$ burden of care, ${ }^{12,13}$ and duration of weaning. ${ }^{12,14}$ No automatic management of oxygenation (i.e., both fraction of inspired oxygen $\left[\mathrm{FIO}_{2}\right]$ and of the positive end-expiratory pressure [PEEP]) was available to date. ${ }^{15,16}$

Intellivent is a new full closed-loop solution for passive and active breathing patients receiving invasive mechanical ventilation and includes automatic adjustment of minute ventilation (MV), $\mathrm{FIO}_{2}$, and PEEP. Intellivent has been studied in sedated, passively ventilated critically ill adult patients with acute respiratory failure, but only for short duration (2-4h). ${ }^{17}$ To our knowledge, no physiological study has been performed to evaluate Intellivent for a longer ventilation period in nonsedated actively breathing critically ill patients and during the weaning period.

The aim of this prospective, randomized, crossover study was to compare ventilatory parameters and gas exchange between Intellivent and PSV given more than $24 \mathrm{~h}$, in critically ill patients, during the weaning phase.

Compared with PSV, which provides a fixed level of assistance $\left(\mathrm{P}_{\text {INSP }}\right)$ regardless of the patient's ventilatory demand, we hypothesized that Intellivent would improve oxygenation by offering more variable ventilation. ${ }^{18,19}$

\section{Materials and Methods}

This single-site study was carried out in the 16-bed medicalsurgical intensive care unit of the St Eloi Hospital, a 660-bed teaching and referral facility of the University of Montpellier in France. The experimental protocol was approved by the Ethics Committee of the Saint-Eloi Teaching Hospital (Comité de Protection des Personnes Sud Méditerranée IV, Montpellier, France), and written informed consent was provided by patient or next of kin. This study followed the CONSORT recommendations concerning randomized trial reporting. ${ }^{20}$

\section{Patients}

From March 2011 to May 2011 (2.5 months), 50 consecutive patients were screened and 16 enrolled. The patients were included if they were in spontaneous mode (active patient, i.e., able to trigger a breath) with an expected duration of invasive mechanical ventilation longer than $48 \mathrm{~h}$. Patients were not included in case of clinical instability, whatever the reason, and when a decision to withhold life-sustaining treatment was made. Pregnant women and children younger than 18 yr were also not included.

\section{General Ventilator Settings}

The two ventilation modes (PSV and Intellivent) were given by the same ventilator (Hamilton S1; Hamilton Medical, Rhäzuns, Switzerland). The rise time $(50 \mathrm{~ms})$, inspiratory flow trigger $(2 \mathrm{l} / \mathrm{min}$ ), and expiratory trigger sensitivity (30\% of the peak flow) were identical in the two modes.

\section{PSV}

In PSV, the $\mathrm{FIO}_{2}$ was set to achieve a pulse oxygen saturation $\left(\mathrm{SpO}_{2}\right)$ greater than $92 \%$ and the PEEP level was set between 5 and $10 \mathrm{~cm} \mathrm{H}_{2} \mathrm{O}$. The level of $\mathrm{P}_{\text {INSP }}$ was adjusted to obtain a VT between 6 and $8 \mathrm{ml} / \mathrm{kg}$ of predicted body weight $(\mathrm{PBW})^{21}$ (as calculated with the following formula for men: PBW $(\mathrm{kg})=50+2.3([$ height $(\mathrm{cm}) / 2.54]$ - 60) and for women: PBW $(\mathrm{kg})=45.5+2.3$ ([height $(\mathrm{cm}) / 2.54]-60)$ and a respiratory rate (RR) between 20 and 30 breaths/min.

\section{Intellivent}

In Intellivent, initial $\mathrm{MV}^{22}$ is automatically determined by the ventilator according to the PBW set by the clinician. The MV is automatically adjusted to maintain end-tidal partial pressure of carbon dioxide $\left(\mathrm{PETCO}_{2}\right)$ within expert-based acceptable ranges ${ }^{23}$ when the patient is not triggering the breath or to maintain the patient's RR within acceptable ranges, as defined by the Otis least work of breathing concept, ${ }^{24}$ when the patient is triggering the breath. To adjust $\mathrm{MV}$ in order to maintain an acceptable range of $\mathrm{PETCO}_{2}$ or $R R$, the ventilator adjusts both the VT and the RR as it is in adaptive support ventilation. ${ }^{4,25}$ In brief, based on the breath-by-breath expiratory time constant $\left(\mathrm{RC}_{\mathrm{EXP}}\right)$ estimation, optimal VT and RR are derived. When MV needs to be adjusted to keep the patient's $\mathrm{PETCO}_{2}$ or RR within the defined range, the ventilator adjusts $P_{\text {INSP }}$ and the mandatory breath to target optimal VT and RR to the patient (appendix 1).

To avoid extreme and potentially dangerous values of VT and RR, Intellivent uses, on a breath-by-breath basis, a safety window for the given $\mathrm{VT}$ and $\mathrm{RR}$ values. The minimal target VT is defined as twice the anatomical dead space estimated from the PBW. The maximal target VT is defined as the maximal pressure (set by the clinician) times the dynamic compliance of the total respiratory system. The minimal value for the target $\mathrm{RR}$ is 5 breaths/min. The maximal value for the target $\mathrm{RR}$ is defined as the ratio $20 / \mathrm{RC}_{\mathrm{EXP}}{ }^{26}$

PEEP and $\mathrm{FIO}_{2}$ are automatically adjusted based on the ARDSnetwork PEEP-FIO ${ }_{2}$ tables ${ }^{27}$ to maintain an $\mathrm{Spo}_{2}$ within expert-based acceptable ranges (appendices 1 and 2). 
The tables are user adjustable by selecting the maximal PEEP delivered. The PEEP/FIO 2 tables from the ARDSnetwork are used only as starting values in the algorithm; but adjustable by the user according to the local policies by setting the maximal PEEP value (appendix 2). Setting low maximal PEEP makes the algorithm adjusting the $\mathrm{FIO}_{2}$ more than the PEEP. In case of moderate decrease in $\mathrm{SpO}_{2}, \mathrm{FIO}_{2}$ increases by $10 \%$ of actual value every $30 \mathrm{~s}$ and PEEP increases by $1 \mathrm{~cm} \mathrm{H}_{2} \mathrm{O}$ every $6 \mathrm{~min}$. If $\mathrm{Spo}_{2}$ is above the target range, $\mathrm{FIO}_{2}$ decreases by $5 \%$ of the actual value every minute and PEEP decreases by $1 \mathrm{~cm} \mathrm{H}_{2} \mathrm{O}$ every $6 \mathrm{~min}$. If $\mathrm{PeTCO}_{2}$ and $\mathrm{Spo}_{2}$ informations are of poor quality or lost, the controllers automatically pause and an alarm is generated. Automatic control is resolved when signal of good quality is measured again. In addition, $\mathrm{FIO}_{2}$ is automatically increased to $100 \%$ if $\mathrm{Spo}_{2}$ is below $85 \%$, and $100 \% \mathrm{FIO}_{2}$ manual bypass is still available. In addition to the adaptive support ventilation safety windows, minimal and maximal $\mathrm{MV}, \mathrm{FIO}_{2}$, and PEEP settings are set by the users before starting Intellivent. By adjusting, on a breath-by-breath basis, the level of $\mathrm{P}_{\text {INSP }}$, RR, PEEP, and $\mathrm{FIO}_{2}$, Intellivent may generate more variability than conventional ventilation such as PSV.

\section{Protocol}

We applied a prospective, randomized, single-blind crossover study design very similar to that previously reported. ${ }^{2,4,28}$ Determination of the first used ventilatory mode (PSV or Intellivent) was randomized. Randomization was carried out using a random-number table. Each patient was consecutively ventilated for $24 \mathrm{~h}$ with the PSV mode and with the Intellivent mode in a random order. Throughout the protocol, suctioning via the endotracheal tube was performed on a per need basis and routine care, such as physiotherapy and nursing was performed as usual in the unit.

\section{Measurements}

Standard three-lead monitoring electrodes continuously monitored heart rate and rhythm. $\mathrm{Spo}_{2}$ was continuously monitored using pulse oximetry. Systolic and diastolic arterial blood pressures were continuously monitored through a 20-gauge catheter inserted in a radial or femoral artery. Blood samples were obtained at baseline (in the first hour after mechanical ventilation for each mode), after 8, 16, and $24 \mathrm{~h}$ of mechanical ventilation for arterial blood gas analysis (GEM Premier 3000 analyzer; Instrumentation Laboratory, Lexington, MA) through the arterial catheter.

The following variables such as airway pressures $\left(\mathrm{P}_{\text {INSP }}\right.$ as inspiratory pressure level above PEEP delivered by the ventilator, $\mathrm{P}_{\text {MEAN }}$ as mean airway pressure, and $\mathrm{P}_{\text {MAX }}$ as maximal airway pressure), VT, RR, MV, $\mathrm{RC}_{\mathrm{EXP}}, \mathrm{PEEP}, \mathrm{FIO}_{2}$, and $\mathrm{PETCO}_{2}$ were collected continuously breath-by-breath, by a dedicated software (Study recorder software; Hamilton Medical) via a RS32 cable, exported through a Universal Serial Bus support and analyzed using a customized software based on Microsoft $\operatorname{Excel}^{\circ}$ (Redmond, WA).
Every $8 \mathrm{~h}$, according to the unit protocol, the nurse in charge of the patient evaluated the pain and comfort using the Behavioral Pain Scale and the sedation and agitation level using the Richmond Agitation Sedation Scale. ${ }^{29,30}$ Setting changes made by the attending physician were also recorded.

\section{Sample Size and Statistical Analysis}

The primary endpoint was oxygenation, estimated by the calculation of the difference between the $\mathrm{PaO}_{2} / \mathrm{FIO}_{2}$ ratio obtained after $24 \mathrm{~h}$ of ventilation and the $\mathrm{PaO}_{2} / \mathrm{FIO}_{2}$ ratio obtained at baseline in each mode. To calculate the number of patients needed, we used data previously published ${ }^{2,31}$ showing in postoperative patients a mean $\mathrm{PaO}_{2} / \mathrm{FIO}_{2}$ ratio of $202 \pm 48 \mathrm{mmHg}$ in PSV. Assuming an $\alpha$ risk of 0.05 and a $\beta$ risk of 0.20 , we calculated that at least 14 patients would be required to identify, after $24 \mathrm{~h}$ of mechanical ventilation, a difference of $20 \%$ between the variation of the $\mathrm{PaO}_{2} / \mathrm{FIO}_{2}$ ratio obtained in Intellivent in comparison to PSV. Therefore, we decided to include 16 patients. The secondary endpoints were the variability in the ventilation variables and the time spent with acceptable ventilation. Ventilation variables were collected continuously breath-by-breath during $24 \mathrm{~h}$ (see above). The variability in the ventilation parameters was evaluated by the coefficients of variation for $\mathrm{P}_{\text {INSP }}$, $R R$, VT, MV, PEEP, $\mathrm{FIO}_{2}, \mathrm{RC}_{\mathrm{EXP}}$, and $\mathrm{PETCO}_{2}$ calculated as the ratio of the $S D$ to the mean multiplied by 100 as previously described. ${ }^{2,32}$ Acceptable ventilation was defined with very permissive ranges, and calculated as the number of breath with RR between 12 and 35 breaths/min, a VT between 5 and $12 \mathrm{ml} / \mathrm{kg}$ of PBW, and $\mathrm{PETCO}_{2}$ less than $55 \mathrm{mmHg}$, over the total number of breath collected. ${ }^{2,27,28}$ Values are expressed as median [interquartile range, IQR] or mean $\pm \mathrm{SD}$ according to the type of variable distribution, from data collected breath-by-breath for $24 \mathrm{~h}$. Normality of the distribution was assessed with Kolmogorov-Smirnov test. Comparisons were performed using Wilcoxon and MannWhitney tests according, and two-tailed $P$ values less than 0.05 were considered significant. Statistical analysis was performed using SAS/STAT software version 8.1 (SAS Institute, Cary, NC) by an independent statistician.

\section{Results}

Among the 16 enrolled patients, 2 did not complete the study because of early extubation, and 14 patients were finally analyzed (fig. 1). There were no safety issues requiring premature interruption of Intellivent for the studied patients. Diagnosis at the time of admission in intensive care unit and clinical characteristics of the patients are shown in table 1. Ventilation settings and main monitored parameters obtained during the first hour after inclusion were shown in table 2 .

Arterial blood gases were shown in the table 3. The $\mathrm{PaO}_{2} /$ $\mathrm{FIO}_{2}$ ratio improved significantly from $245 \pm 75$ at baseline to $294 \pm 123 \mathrm{mmHg}(P=0.035)$ after $24 \mathrm{~h}$ of Intellivent, 


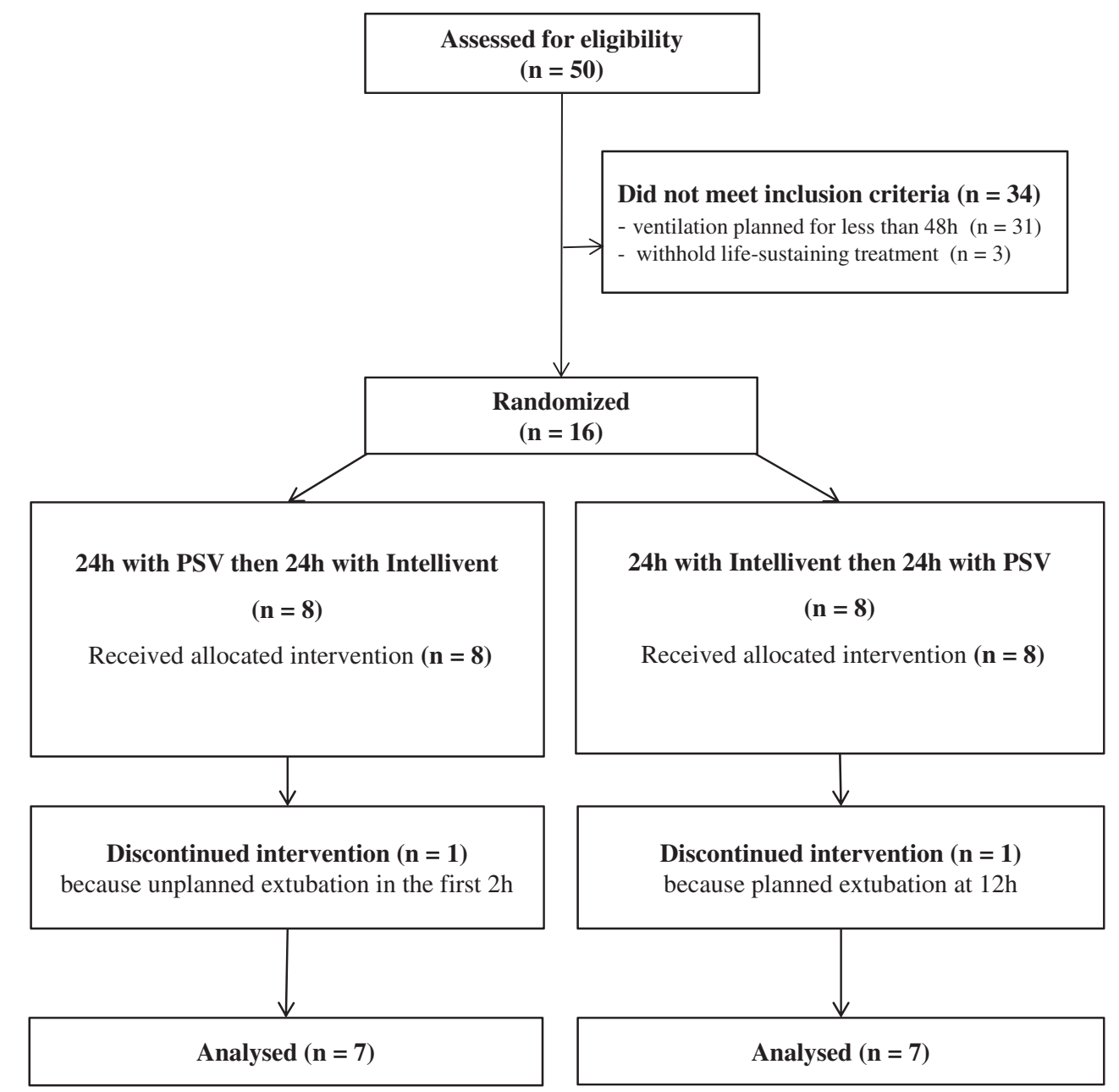

Fig. 1. Trial profile. PSV = pressure support ventilation.

Table 1. Characteristics of the 14 Patients Studied

\begin{tabular}{|c|c|c|c|c|c|c|}
\hline Patient & Sex & Age, yr & Height, $\mathrm{cm}$ & Weight, kg & BMI, $\mathrm{kg} / \mathrm{m}^{2}$ & SAPS II \\
\hline$\overline{1}$ & $\bar{M}$ & 32 & 174 & 70 & 23 & 37 \\
\hline 2 & $\mathrm{~F}$ & 52 & 154 & 46 & 19 & 38 \\
\hline 3 & $M$ & 62 & 180 & 112 & 35 & 55 \\
\hline 4 & $\mathrm{M}$ & 46 & 170 & 68 & 23 & 33 \\
\hline 5 & M & 65 & 175 & 87 & 28 & 42 \\
\hline 6 & $\mathrm{~F}$ & 56 & 165 & 90 & 33 & 55 \\
\hline 7 & $\mathrm{~F}$ & 21 & 170 & 72 & 25 & 23 \\
\hline 8 & $\mathrm{M}$ & 71 & 160 & 58 & 23 & 34 \\
\hline 9 & $\mathrm{~F}$ & 50 & 168 & 141 & 50 & 31 \\
\hline 10 & $M$ & 61 & 180 & 110 & 34 & 58 \\
\hline 11 & $\mathrm{M}$ & 52 & 173 & 80 & 27 & 61 \\
\hline 12 & $\mathrm{M}$ & 68 & 170 & 90 & 31 & 29 \\
\hline 13 & $\mathrm{M}$ & 83 & 170 & 71 & 25 & 67 \\
\hline \multirow[t]{2}{*}{14} & $\mathrm{M}$ & 62 & 162 & 71 & 27 & 38 \\
\hline & - & 58 [50-64] & 170 [166-174] & 76 [70-30] & 27 [24-33] & $38[33-55]$ \\
\hline
\end{tabular}

Data are presented as median [interquartile range].

$\mathrm{BMI}$ = body mass index; F = female; $\mathrm{M}$ = male; SAPS II = Simplified Acute Physiology Score II. 
whereas no significant change was observed with PSV (fig. 2). The $\mathrm{PaO}_{2} / \mathrm{FIO}_{2}$ ratio variation after $24 \mathrm{~h}$ of mechanical ventilation was significantly higher in Intellivent than in PSV mode $(+18 \pm 32 \%$ vs. $-3 \pm 20 \% ; P=0.026)$.

The $24-\mathrm{h}$ average values of the ventilation parameters are reported in table 4 . VT was $7.6 \mathrm{ml} / \mathrm{kg}$ [IQR, 6.6-9.0] during PSV period compared with $8.4 \mathrm{ml} / \mathrm{kg}$ [IQR, 7.9-8.6] PBW during Intellivent period $(P=0.04)$. The $\mathrm{RR}$ was 22 breaths/ min [IQR, 19-27] during PSV period compared with 19 breaths/min [IQR, 15-22] during Intellivent period $(P=0.01)$. Typical tracings obtained during $24 \mathrm{~h}$ of both PSV and Intellivent are shown in figure 3. There is obviously more variability in $\mathrm{P}_{\text {INSP }}$, PEEP, and $\mathrm{FIO}_{2}$ with Intellivent as compared with PSV. The coefficient of variation of $\mathrm{P}_{\text {INSP }}$ and PEEP was significantly higher with Intellivent as compared with PSV (table 4).

Times spent in different ranges of VT, RR, and $\mathrm{PeTCO}_{2}$ in both modalities are shown in figure 4 . The number of changes in $\mathrm{P}_{\text {INSP }}$, PEEP, and $\mathrm{FIO}_{2}$ was significantly higher with Intellivent compared with PSV (table 5). No significant differences were observed between the two modes for the Behavioral Pain Scale and Richmond Agitation Sedation Scale scores over the study period.

\section{Discussion}

The current study demonstrates that over a 24-h study period, ventilation with Intellivent was associated with a higher $\mathrm{PaO}_{2} /$ $\mathrm{FIO}_{2}$ ratio and a greater variability in $\mathrm{P}_{\text {INSP }}$ and PEEP compared with PSV. In addition, the study suggests that the use of Intellivent for $24 \mathrm{~h}$ of mechanical ventilation is feasible and safe for critically ill patients during the weaning period.

The current study is the first to report long-term (i.e., 24-h period) safe use of the Intellivent mode and to associate its use with improvement in oxygenation. The improvement in oxygenation observed with Intellivent is probably not related to a single mechanism, but we could speculate that it is because of more complex association of different features of Intellivent. Some features related to Intellivent can be proposed such as a slight, but significantly, higher airway pressures $\left(\mathrm{P}_{\text {INSP }}\right.$ and $\mathrm{P}_{\text {MAX }}$, not $\mathrm{P}_{\text {MEAN }}$ ) leading a higher VT (table 4 ), an increase in variability of inspiratory pressures and PEEP, which may assimilated to more physiological sigh, and be considered as repeated alveolar auto-recruitment. Although, median VT was significantly higher in Intellivent than in PSV (8.4 [IQR, 7.9-8.6] vs. 7.6 [IQR, 6.6-9.0] $\mathrm{ml} / \mathrm{kg}$ PBW; $P=0.04$; table 4 ), VT remained lower than $10 \mathrm{ml} / \mathrm{kg}$ PBW more than $90 \%$ of the time spent in each modes with no significant difference between both Intellivent and PSV (fig. 4). Indeed, risk factors to develop acute lung injury or acute respiratory distress syndrom in passive ventilated patients are VT above $10 \mathrm{ml} / \mathrm{kg} \mathrm{PBW}$ and an endinspiratory pressure above $30 \mathrm{~cm} \mathrm{H}_{2} \mathrm{O}$. In the current study, no patient was passively ventilated, and the association of a VT above $10 \mathrm{ml} / \mathrm{kg}$ PBW and an end-inspiratory pressure above $30 \mathrm{~cm} \mathrm{H} \mathrm{H}_{2} \mathrm{O}$ occurred together exceptionally either in Intellivent or PSV. Low VT with subsequently high transpulmonary pressure may basically be more dangerous than higher VT with lower transpulmonary pressure. In combination with more variability in airway pressures $\left(\mathrm{P}_{\text {INSP }}, \mathrm{P}_{\text {MAX }}\right.$, and $\mathrm{P}_{\text {MEAN }}$ ) and in PEEP with Intellivent, it suggests causality between Intellivent-induced variability and improvement in oxygenation. Several publications have already reported better oxygenation when pressure or volume applied to the respiratory system is variable, whatever the mode of ventilation being used. 2,7,8,33 The current study can only speculate on the mechanism responsible for such improvement. The Jensen inequality, i.e., the local nonlinear pressure-volume relationship, has been suggested as a mechanistic explanation, ${ }^{34,35}$ heterogeneity in local time constant, ${ }^{17,36}$ improved

\begin{tabular}{lcccc}
\hline & $\begin{array}{c}\text { Number of Days after } \\
\text { Intubation and } \\
\text { Enrolment }\end{array}$ & $\begin{array}{c}\text { Number of Days after } \\
\text { Weaning Started } \\
\text { and Enrolment }\end{array}$ & $\begin{array}{c}\text { Total } \\
\text { Duration of } \\
\text { Ventilation, d }\end{array}$ & Outcome \\
\hline Siagnosis in Intensive Care Unit & 1 & 1 & 16 & Died \\
Liver transplant & 1 & 1 & 4 & Survived \\
Septic shock-peritonitis & 4 & 3 & 7 & Survived \\
Liver traumatism & 5 & 1 & 14 & Survived \\
Septic shock-pneumonia & 4 & 1 & 10 & Died \\
Pneumonia & 6 & 3 & 9 & Survived \\
Liver transplant & 2 & 1 & 4 & Survived \\
Peritonitis & 1 & 1 & 9 & Died \\
Peritonitis & 1 & 1 & 5 & Survived \\
Septic shock-peritonitis & 3 & 2 & 6 & Survived \\
Hepatic encephalitis & 1 & 1 & 3 & Survived \\
Septic shock-pneumonia & 2 & 1 & 6 & Survived \\
Peritonitis & 3 & 2 & 11 & Survived \\
Polytraumatized & 8 & 1 & 24 & Survived \\
& $2[1-4]$ & $1[1-2]$ & 8 [5-11] & - \\
\hline
\end{tabular}


Table 2. Ventilation Settings and Main Monitored Parameters Obtained the First Hour after Inclusion in PSV and Intellivent

\begin{tabular}{|c|c|c|c|}
\hline Parameters & PSV $(n=14)$ & Intellivent $(n=14)$ & $P$ Value \\
\hline \multicolumn{4}{|l|}{ Manual ventilation settings } \\
\hline Pressure support level, $\mathrm{cm} \mathrm{H}_{2} \mathrm{O}$ & $11.0[7.8-12.0]$ & NA & NA \\
\hline Fraction of inspired oxygen, \% & 35 [30-40] & NA & NA \\
\hline PEEP, $\mathrm{cm} \mathrm{H} \mathrm{H}_{2} \mathrm{O}$ & $7.5[5.0-9.5]$ & NA & NA \\
\hline \multicolumn{4}{|l|}{ Automatic ventilation settings } \\
\hline$\% \mathrm{MV}, \%$ & NA & $104[100-142]$ & NA \\
\hline Fraction of inspired oxygen, \% & NA & 30 [30-32] & NA \\
\hline PEEP, $\mathrm{cm} \mathrm{H} \mathrm{H}_{2} \mathrm{O}$ & NA & $5.5[5.0-6.8]$ & NA \\
\hline \multicolumn{4}{|l|}{ Monitored parameters } \\
\hline $\mathrm{Spo}_{2}, \%$ & 97.5 [97.0-98.8] & 96.5 [96.0-97.8] & 0.063 \\
\hline $\mathrm{P}_{\text {INSP }}, \mathrm{cm} \mathrm{H}_{2} \mathrm{O}$ & $11.0[9.5-12.0]$ & $10.4[8.7-14.0]$ & 0.055 \\
\hline $\mathrm{RR}$, breaths/min & $21[16-25]$ & 20 [15-22] & 0.637 \\
\hline VT, ml/kg PBW & 7.5 [7.2-9.3] & $8.3[7.3-9.3]$ & 0.432 \\
\hline $\mathrm{MV}, \mathrm{I} / \mathrm{min}$ & $10.3[9.6-12.3]$ & $10.4[9.6-12.1]$ & 0.851 \\
\hline $\mathrm{PETCO}_{2}, \mathrm{mmHg}$ & 37 [34-40] & $40[35-41]$ & 0.342 \\
\hline $\mathrm{RC}_{\mathrm{EXP}}, \mathrm{s}$ & $0.64[0.54-0.76]$ & $0.63[0.49-0.73]$ & 0.975 \\
\hline
\end{tabular}

Data are presented as median [interquartile range].

$\mathrm{MV}$ = minute ventilation; \%MV = percentage of minute ventilation; $N A=$ not applicable; $N S$ = not significant; PEEP = positive endexpiratory pressure; $\mathrm{PETCO}_{2}=$ end-tidal partial pressure of carbon dioxide; $\mathrm{P}_{\mathrm{INSP}}=$ inspiratory airway pressure; $\mathrm{PBW}=$ predicted body weight; $\mathrm{PSV}=$ pressure support ventilation; $\mathrm{RC}_{\mathrm{EXP}}=$ expiratory time constant; $\mathrm{RR}=$ respiratory rate; $\mathrm{SpO}_{2}=$ pulsatile oxygen saturation; VT = tidal volume

surfactant production, ${ }^{37}$ and improved ventilation-perfusion matching ${ }^{38}$ may also play a role in better oxygenation with more variable ventilation.

More ventilator adjustments were made during Intellivent ventilation compared with PSV. Although expected with closed-loop systems, which are by design able to continuously adjust the ventilatory parameters according to the changes in patient's condition, it is worthwhile discussing the possible impact of adjusting the ventilator more often. First, as already discussed earlier, more adjustment makes ventilation more variable, and this may have clinical impacts (such as oxygenation in the current study). Second, it may help to maintain the patient within predefined acceptable ventilation ranges. In the current study,

Table 3. Arterial Blood Gases between PSV and Intellivent

\begin{tabular}{|c|c|c|c|c|c|}
\hline & $\mathrm{H} 1$ & $\mathrm{H} 8$ & $\mathrm{H} 16$ & $\mathrm{H} 24$ & $P$ Value \\
\hline \multicolumn{6}{|l|}{$\mathrm{pH}$} \\
\hline PSV & $7.43[7.39-7.45]$ & $7.42[7.38-7.47]$ & $7.42[7.37-7.45]$ & $7.42[7.37-7.47]$ & 0.997 \\
\hline Intellivent & $7.40[7.37-7.45]$ & $7.42[7.38-7.46]$ & $7.41[7.39-7.45]$ & $7.44[7.38-7.47]$ & 0.618 \\
\hline \multicolumn{6}{|c|}{$\mathrm{PacO}_{2}, \mathrm{mmHg}$} \\
\hline PSV & $39.0[37.0-44.8]$ & 40.5 [37.0-48.5] & $42.0[37.0-46.8]$ & $42.0[39.5-46.5]$ & 0.922 \\
\hline Intellivent & $40.5[36.5-44.5]$ & $40.0[38.0-43.8]$ & $40.5[36.8-44.0]$ & $41.0[36.0-42.8]$ & 0.891 \\
\hline \multicolumn{6}{|l|}{$\mathrm{PaO}_{2}, \mathrm{mmHg}$} \\
\hline PSV & $97.0[72.5-121.0]$ & 95.0 [86.3-108.8] & 96.5 [84.3-105.3] & 90.5 [75.0-110.5] & 0.625 \\
\hline Intellivent & $72.0[66.5-79.8]^{\star}$ & $74.5[69.3-90.3]^{\star}$ & $74.0[66.0-90.0]$ & $78.5[67.5-107.8]$ & 0.496 \\
\hline \multicolumn{6}{|c|}{ Plasma bicarbonate, mM } \\
\hline PSV & 24.5 [22.0-29.2] & $25.6[23.3-29.4]$ & $26.0[23.3-30.5]$ & 26.0 [24.0-31.5] & 0.969 \\
\hline Intellivent & $23.9[21.3-31.1]$ & $24.5[22.3-30.5]$ & 25.5 [22.5-30.6] & 26.0 [21.4-29.2] & 0.335 \\
\hline \multicolumn{6}{|l|}{$\mathrm{SaO}_{2}(\%)$} \\
\hline PSV & 98.0 [94.5-98.8] & 98.0 [97.0-98.0] & 97.5 [97.0-98.0] & 97.5 [95.3-98.0] & 0.939 \\
\hline Intellivent & $94.5[92.8-96.5]^{\star}$ & $94.5[92.2-96.2]^{*}$ & $95.0[93.3-96.8]^{\star}$ & 96.0 [93.3-98.5] & 0.335 \\
\hline
\end{tabular}

Data are presented as median [interquartile range].

${ }^{*} P<0.05$ between PSV and Intellivent.

$\mathrm{PaCO}_{2}=$ arterial pressure of carbon dioxide; $\mathrm{PaO}_{2}=$ arterial pressure of oxygen; $\mathrm{PSV}=$ pressure support ventilation; $\mathrm{SaO}{ }_{2}=$ oxygen saturation of arterial blood. 
A

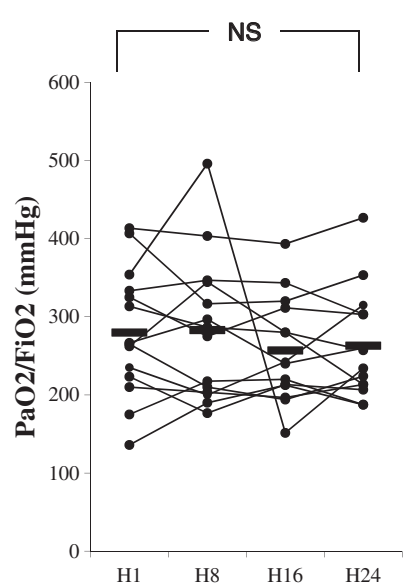

B

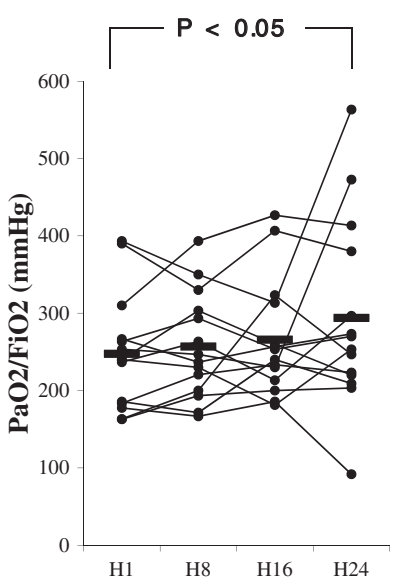

Fig. 2. Individual variations in $\mathrm{PaO}_{2} / \mathrm{FIO}_{2}$ ratio for the 14 patients after mechanical ventilation with pressure support ventilation (PSV; $A$ ) and with Intellivent $(B)$. The horizontal bars represent the mean values. $P$ value refers to the test of the first versus the last time point. $\mathrm{FlO}_{2}=$ inspired oxygen fraction; $\mathrm{NS}=$ not significant; $\mathrm{PaO}_{2}=$ partial pressure of arterial oxygen.

time spent by the patient with acceptable ventilation during Intellivent was not very different compared with PSV (fig. 4). However, during Intellivent, 11 of 14 patients (76\%) spent more than $90 \%$ of ventilation time in acceptable ventilation (as defined in the methodology section) as compared with only 5 patients with PSV $(P=0.04)$. In other studies, ${ }^{39,40}$ Intellivent was able to keep the patient more often with acceptable ventilation. In these studies, ${ }^{39,40}$ most of the patients were not triggering the breath

and were therefore fully controlled by the ventilator. In the current study, all patients were able to trigger the breath and to control their breathing pattern at least partially. The definition of "acceptable ventilation", which was relatively permissive in the current study (because of the selected population), is indeed also important in analyzing the results and can be extensively discussed. Finally, although not analyzed in the current study, the number of ventilator adjustments with Intellivent may reflect how often the ventilator should be adjusted, whereas the number of changes in PSV may reflect basically how often the ventilator can be adjusted manually considering human resources and knowledge available at the bedside day and night. The current study is definitely not able to draw any conclusions on possible clinical impact of continuous and more frequent adjustments of the ventilator but give enough confidence to design large randomized controlled trials to address such a question. In addition, the current study is the first to report the use of Intellivent for more than couple of hours, in adult patients with variable conditions and during the weaning phase.

All patients were able to complete the study, and no patients were removed from Intellivent for major safety issues, suggesting that 24-h use of Intellivent may be safe in critically ill patients during the weaning period.

This study has some limitations. The study was not designed to evaluate the safeness and effectiveness of Intellivent as a routine mode of ventilation in patients in intensive care unit and therefore is underpowered for that. Interestingly, in three patients, $\mathrm{FIO}_{2}$ had to be adjusted

Table 4. Ventilation Parameters with PSV and with Intellivent

\begin{tabular}{|c|c|c|c|c|c|c|}
\hline & \multicolumn{2}{|c|}{ Median } & \multirow[b]{2}{*}{$P$ Value } & \multicolumn{2}{|c|}{ Coefficient of Variation, \% } & \multirow[b]{2}{*}{$P$ Value } \\
\hline & $\begin{array}{c}\text { PSV } \\
(n=14)\end{array}$ & $\begin{array}{l}\text { Intellivent } \\
(\mathrm{n}=14)\end{array}$ & & $\begin{array}{c}\text { PSV } \\
(n=14)\end{array}$ & $\begin{array}{l}\text { Intellivent } \\
(\mathrm{n}=14)\end{array}$ & \\
\hline $\mathrm{P}_{\text {INSP }}, \mathrm{cm} \mathrm{H}_{2} \mathrm{O}$ & 12 [10-13] & 14 [12-18] & 0.013 & $10[8-18]$ & 21 [13-25] & 0.019 \\
\hline $\mathrm{P}_{\text {MEAN }}^{\text {INSP }}, \mathrm{cm} \mathrm{H}_{2} \mathrm{O}$ & $11[8-13]$ & $10[8-13]$ & 0.40 & $6[5-7]$ & $16[11-21]$ & 0.01 \\
\hline $\mathrm{P}_{\text {MAX }}, \mathrm{cm} \mathrm{H}_{2} \mathrm{O}$ & 20 [16-21] & 22 [18-25] & 0.006 & 7 [5-9] & 15 [10.4-17.9] & 0.006 \\
\hline $\mathrm{RR}$, breaths/min & 22 [19-27] & 19 [15-22] & 0.01 & 19 [16-25] & 20 [18-28] & 0.14 \\
\hline VT, ml/kg PBW & 7.6 [6.6-9.0] & 8.4 [7.9-8.6] & 0.04 & $20[16-24]$ & 16 [14-23] & 0.53 \\
\hline $\mathrm{MV}, \mathrm{I} / \mathrm{min}$ & 10.9 [9.4-12.0] & 11.0 [9.7-11.4] & 0.37 & $16[13-18]$ & 16 [13-21] & 0.37 \\
\hline $\begin{array}{l}\text { Compliance, } \mathrm{ml} / \\
\mathrm{cm} \mathrm{H}_{2} \mathrm{O}\end{array}$ & 59 [49-84] & 55 [42-80] & 0.12 & 25 [20-27] & 27 [20-45] & 0.27 \\
\hline $\mathrm{RC}_{\mathrm{EXP}}, \mathrm{s}$ & $0.58[0.51-0.74]$ & $0.61[0.53-0.71]$ & 0.41 & 16 [12-20] & 16 [13-23] & 0.17 \\
\hline $\mathrm{PETCO}_{2}, \mathrm{mmHg}$ & 38.5 [34.3-41.2] & 37.8 [34.5-39.5] & 0.47 & 7 [6-8] & $6[5-8]$ & 0.24 \\
\hline $\mathrm{Spo}_{2}, \%$ & $98.0[96.7-98.5]$ & 96.2 [95.0-97.0] & 0.02 & $1[1-2]$ & $1[1-2]$ & 0.63 \\
\hline $\mathrm{FIO}_{2}, \%$ & $33.4[30.0-41.4]$ & $31.1[30.0-32.4]$ & 0.13 & $0.2[0.0-8.0]$ & $13[4-20]$ & 0.05 \\
\hline PEEP, $\mathrm{cm} \mathrm{H}_{2} \mathrm{O}$ & 7.8 [5.0-9.7] & 5.4 [5.0-7.8] & 0.31 & 7 [5-10] & 15 [7-23] & 0.01 \\
\hline
\end{tabular}

Data are presented as median [interquartile range].

$\mathrm{FIO}_{2}=$ oxygen inspirited fraction; $\mathrm{MV}=$ minute ventilation; $\% \mathrm{MV}=$ percentage of minute ventilation; $\mathrm{NA}=$ not applicable; NS = not significant; PBW = predicted body weight; PEEP = positive end-expiratory pressure; $\mathrm{PETCO}_{2}=$ end-tidal partial pressure of carbon dioxide; $\mathrm{P}_{\text {INSP }}=$ inspiratory pressure level above PEEP delivered by the ventilator; $\mathrm{P}_{\text {max }}=$ maximal airway pressure; $\mathrm{P}_{\text {mEAN }}=$ mean airway pressure; $\mathrm{PSV}=$ pressure support ventilation; $\mathrm{RC}_{\mathrm{EXP}}=$ expiratory time constant; $\mathrm{RR}=$ respiratory rate; $\mathrm{SpO}_{2}=$ pulsatile saturation in oxygen; $\mathrm{VT}=$ tidal volume. 


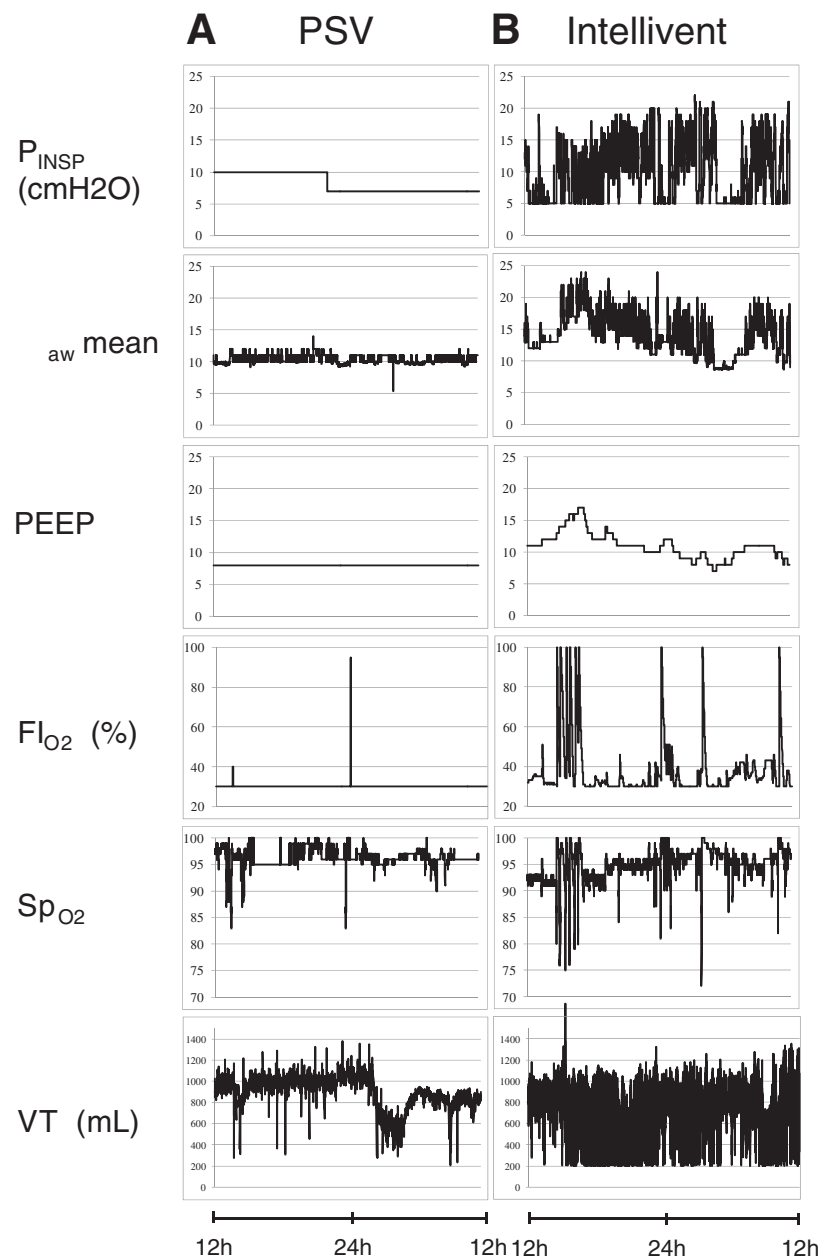

Fig. 3. Experimental records that help in illustrating the effects of the two ventilatory modes during $24 \mathrm{~h}$ of mechanical ventilation with pressure support ventilation (PSV; $A$ ) and with Intellivent $(B)$ in a representative patient. From top to bottom, inspiratory pressure above end-expiratory pressure $\left(P_{\text {INSP }}\right)$, mean airway pressure $\left(\mathrm{P}_{\text {MEAN }}\right)$, positive end-expiratory pressure (PEEP), fraction of inspired oxygen $\left(\mathrm{FIO}_{2}\right)$, pulsatile oxygen saturation $\left(\mathrm{SpO}_{2}\right)$, and tidal volume $(\mathrm{VT})$. Note that $\mathrm{P}_{\text {INSP }}, \mathrm{P}_{\text {MEAN }}$, PEEP, and $\mathrm{FIO}_{2}$ are more variable in Intellivent than in PSV.

manually because of a discrepancy between $\mathrm{Spo}_{2}$ and $\mathrm{SaO}_{2}$ obtained from arterial blood sampling. However, because of the population selection (few hypoxemic patients), the $\mathrm{FIO}_{2}$ and PEEP algorithms and the robustness of $\mathrm{SpO}_{2}$ information (filtering, artifact, and motion rejections, and so on) for running the loops were not really challenged in the current study. Moreover, although we evaluated the agitation and sedation-analgesia levels every $4 \mathrm{~h}$ (using Richmond Agitation Sedation Scale and Behavioral Pain Scale scores), there was no specific auto-evaluation of the ventilatory comfort.

\section{Conclusions}

The current prospective study is the first to report 24-h use of Intellivent in spontaneously breathing patients during
A

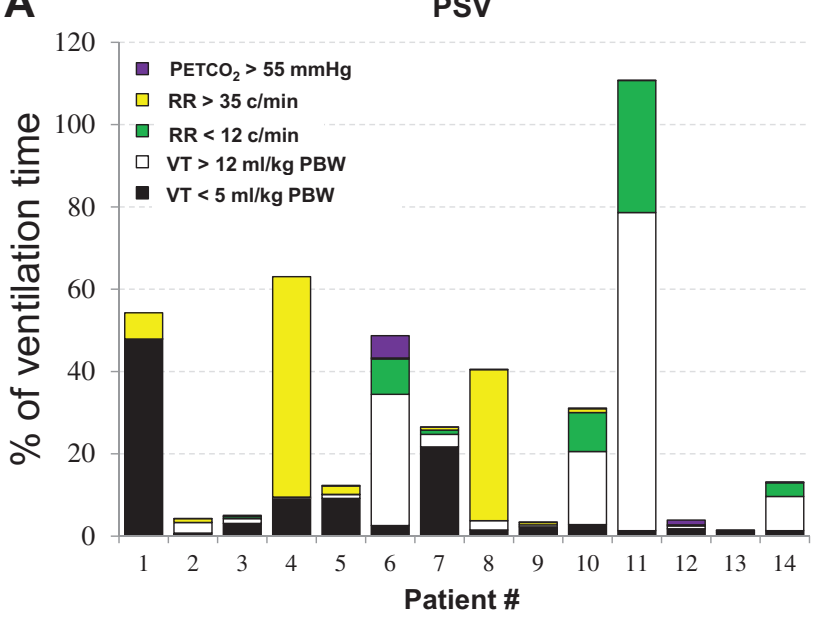

B

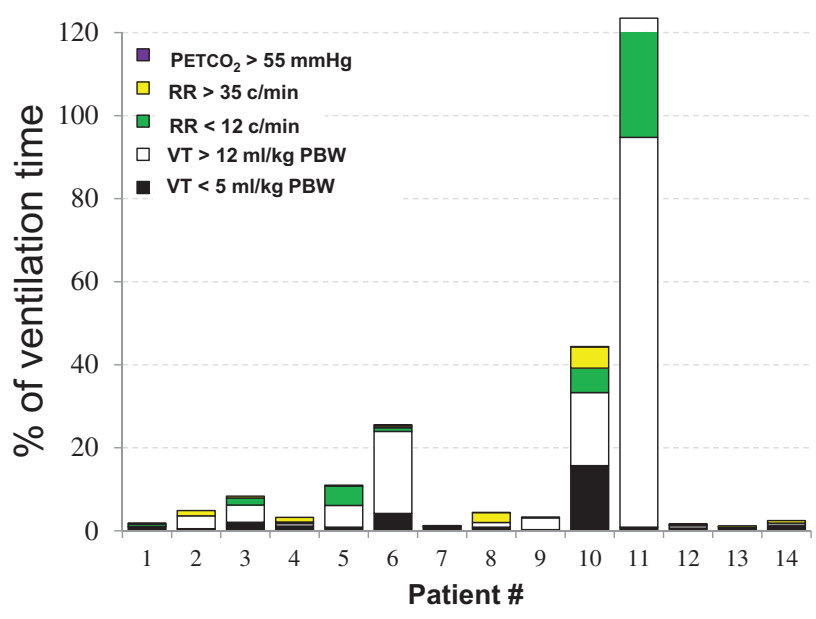

Fig. 4. Contributions to inadequate ventilation of low tidal volume (VT) of $<5 \mathrm{ml} / \mathrm{kg}$ of predicted body weight (PBW), high VT of $>12 \mathrm{ml} / \mathrm{kg}$ PBW, low respiratory rate (RR) of $<12$ breaths/ min, high RR of $>35$ breaths/min, and high end-tidal partial pressure of carbon dioxide $\left(\mathrm{PETCO}_{2}\right)$ of $>55 \mathrm{mmHg}$ during the $24 \mathrm{~h}$ of pressure support ventilation (PSV, $A$ ) and $24 \mathrm{~h}$ of Intellivent $(B)$ in the 14 studied patients. A patient can be in adequate ventilation for low RR and high VT, at the same time that may explain why patient number 11 spent more than $100 \%$ of the time in inadequate ventilation with Intellivent. With PSV, inadequate ventilation represented $17.1 \%$ [interquartile range, 4.3-39.6] of the total ventilation duration in this mode; with Intellivent, inadequate ventilation represented 3.7\% [interquartile range, 1.8-10.1] of the total ventilation duration in this mode.

the weaning process. As compared with PSV, the $\mathrm{PaO}_{2} / \mathrm{FIO}_{2}$ ratio at $24 \mathrm{~h}$ was improved in Intellivent with more variability in airway pressures, PEEP, and $\mathrm{FIO}_{2}$. Adjustment of the ventilator was much more frequent with Intellivent as compared with PSV, which may explain the variability and ultimately the better oxygenation observed with Intellivent. The current study definitely warrants further prospective controlled studies to estimate the potential clinical impact of Intellivent as compared with conventional modes of ventilation. 
Table 5. Number of Changes in $\mathrm{P}_{\mathrm{INSP}}$, PEEP, and $\mathrm{FIO}_{2}$ during PSV and Intellivent

\begin{tabular}{|c|c|c|c|c|c|c|}
\hline \multirow[b]{2}{*}{ Patients } & \multicolumn{2}{|c|}{$\begin{array}{l}\text { Changes in } \mathrm{P}_{\text {INSP }} \\
\text { No. of Events }\end{array}$} & \multicolumn{2}{|c|}{$\begin{array}{l}\text { Changes in PEEP } \\
\text { No. of Events }\end{array}$} & \multicolumn{2}{|c|}{$\begin{array}{l}\text { Changes in } \mathrm{FlO}_{2} \\
\text { No. of Events }\end{array}$} \\
\hline & PSV & Intellivent & PSV & Intellivent & PSV & Intellivent \\
\hline 1 & 3 & 1,347 & 0 & 5 & 9 & 4 \\
\hline 2 & 0 & 2,384 & 0 & 4 & 0 & 0 \\
\hline 3 & 0 & 4,125 & 0 & 34 & 1 & 155 \\
\hline 4 & 3 & 2,127 & 0 & 26 & 2 & 175 \\
\hline 5 & 0 & 4,999 & 0 & 6 & 1 & 8 \\
\hline 6 & 1 & 2,910 & 0 & 19 & 0 & 32 \\
\hline 7 & 1 & 1,748 & 0 & 4 & 0 & 103 \\
\hline 8 & 2 & 2,416 & 0 & 12 & 0 & 137 \\
\hline 9 & 2 & 2,164 & 3 & 10 & 1 & 189 \\
\hline 10 & 2 & 4,283 & 0 & 42 & 4 & 515 \\
\hline 11 & 2 & 113 & 0 & 0 & 0 & 0 \\
\hline 12 & 1 & 2,037 & 1 & 13 & 0 & 0 \\
\hline 13 & 0 & 345 & 1 & 17 & 1 & 70 \\
\hline 14 & 0 & 1,850 & 1 & 14 & 1 & 339 \\
\hline $\begin{array}{l}\text { Median [interquartile } \\
\text { range] }\end{array}$ & 1 [0-2] & $2,146[1,774-2,787]^{\star \star}$ & $0[0-1]$ & $13[5-19]^{\star \star}$ & $1[0-1]$ & $87[5-170]^{\star *}$ \\
\hline
\end{tabular}

${ }^{* \star} P<0.01$ between PSV and Intellivent.

$\mathrm{FIO}_{2}=$ fraction of inspired oxygen; $\mathrm{PEEP}$ = positive end-expiratory pressure; $\mathrm{P}_{\mathrm{INSP}}=$ inspiratory airway pressure; $\mathrm{PSV}=$ pressure support ventilation.

\section{Appendix 1. Ventilation and Oxygenation Controllers}

\section{$\underline{\text { Ventilation }}$}

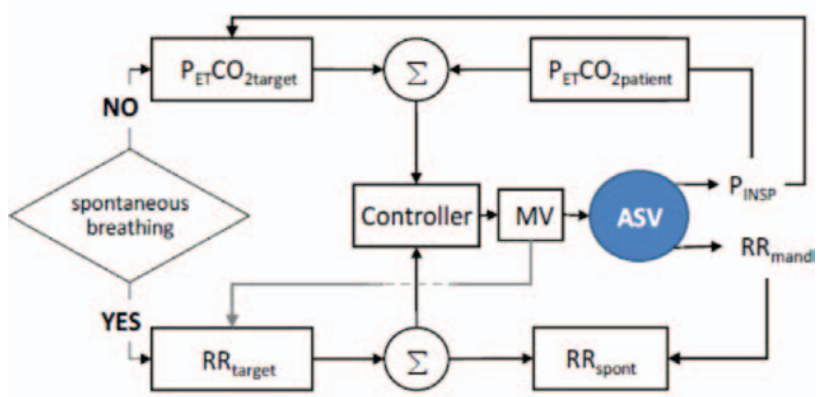

\section{Oxygenation}

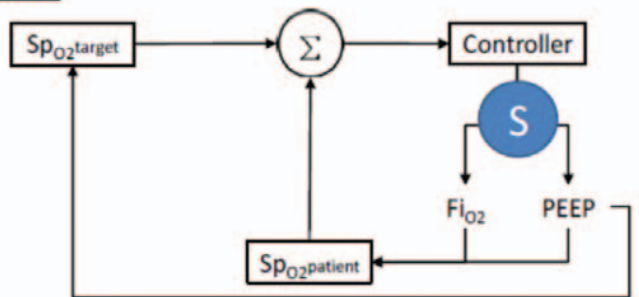

Fig. 5. Ventilation controller: First of all, the system detected whether the patient is spontaneously breathing (based on consecutive number of breaths triggered by the patient). If the patient is not spontaneously breathing, the regulation is based on end-tidal partial pressure of carbon dioxide $\left(\mathrm{PETCO}_{2}\right)$ and if the patient's $\mathrm{PETCO}_{2}$ is outside the target ranges, the controller adjusts minute ventilation (MV): increasing if $\mathrm{PETCO}_{2}$ is above the target range and decreasing if $\mathrm{PETCO}_{2}$ is below the target range. If the patient is spontaneously breathing, the regulation is based on the respiratory rate (RR) and if the patient's
$\mathrm{RR}$ (RRspont) is outside the target range, MV is adjusted: increasing MV if the patient RR is above the target range and decreasing if the patient $R R$ is below the target range. In both situations, changes in MV are going through the adaptive support ventilation (ASV) controller, which is deciding whether the mandatory RR (RRmand) or the level of inspiratory pressure $\left(\mathrm{P}_{\text {INSP }}\right)$ should be adjusted. There is an adjustment of the $\mathrm{PETCO}_{2}$ target range based on the level of $\mathrm{P}_{\text {INSP }}$ : the higher the $\mathrm{P}_{\text {INSP, }}$, the more permissive the target ranges. There is also an adjustment of the RR target range based on MV: the higher the MV, the wider that the RR target range. Oxygenation controller: The patient's pulsatile oxygen saturation $\left(\mathrm{SpO}_{2}\right)$ value is compared with $\mathrm{Spo}_{2}$ target range, and if the patient's $\mathrm{Spo}_{2}$ is outside the target, the controller is adjusting the fraction of inspired oxygen $\left(\mathrm{FIO}_{2}\right)$ or the positive end-expiratory pressure (PEEP), depending on the selector (S). The choice between PEEP and $\mathrm{FIO}_{2}$ is based on a predefined PEEP-FIO table which is adjustable depending on the user-set maximal PEEP. There is an adjustment of the target $\mathrm{SpO}_{2}$ depending on the PEEP value: the higher the PEEP, the more permissive is the target. In case of moderate decrease in $\mathrm{Spo}_{2}, \mathrm{FIO}_{2}$ increases by $10 \%$ of actual value every $30 \mathrm{~s}$ and PEEP increases by $1 \mathrm{~cm} \mathrm{H}_{2} \mathrm{O}$ every $6 \mathrm{~min}$. If $\mathrm{SpO}_{2}$ is above the target range, $\mathrm{FIO}_{2}$ decreases by $5 \%$ of the actual value every minute and PEEP decreases by $1 \mathrm{~cm} \mathrm{H}_{2} \mathrm{O}$ every $6 \mathrm{~min}$. A minimal PEEP level can be set by the user which may limit in some cases a rapid decrease in PEEP which may result in derecruitment over time. If $\mathrm{PETCO}_{2}$ and $\mathrm{SpO}_{2}$ informations are of poor quality or lost, the controllers automatically pause and an alarm is generated. Automatic control is resolved when signal of good quality is measured again. In addition, $\mathrm{FIO}_{2}$ is automatically increased to $100 \%$ if $\mathrm{SpO}_{2}$ is below $85 \%$, and $100 \% \mathrm{FIO}_{2}$ manual bypass is still available. 


\section{Appendix 2. PEEP-FIO ${ }_{2}$ Table Algorithm}

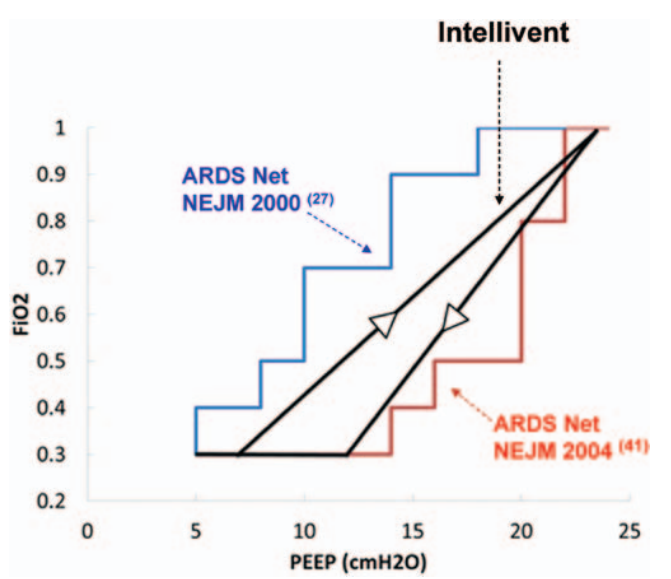

Fig. 6. Positive end-expiratory pressure (PEEP) and fraction of inspired oxygen $\left(\mathrm{F}_{1} \mathrm{O}_{2}\right)$ are automatically adjusted based on the ARDSnetwork PEEP-FIO ${ }_{2}$ tables ${ }^{27,41}$ to maintain pulsatile oxygen saturation $\left(\mathrm{Spo}_{2}\right)$ within expert-based acceptable ranges. The tables are user adjustable by selecting the maximal PEEP delivered. The PEEP/FIO ${ }_{2}$ tables from the ARDSnetwork are used only as starting values in the algorithm; but adjustable by the user according to the local policies by setting the maximal PEEP value.

\section{References}

1. Peñuelas O, Frutos-Vivar F, Fernández C, Anzueto A, Epstein SK, Apezteguía C, González M, Nin N, Raymondos K, Tomicic V, Desmery P, Arabi Y, Pelosi P, Kuiper M, Jibaja M, Matamis D, Ferguson ND, Esteban A; Ventila Group: Characteristics and outcomes of ventilated patients according to time to liberation from mechanical ventilation. Am J Respir Crit Care Med 2011; 184:430-7

2. Coisel Y, Chanques G, Jung B, Constantin JM, Capdevila X, Matecki S, Grasso S, Jaber S: Neurally adjusted ventilatory assist in critically ill postoperative patients: A crossover randomized study. ANESTHESIOLOGY 2010; 113:925-35

3. Jaber S, Delay JM, Matecki S, Sebbane M, Eledjam JJ, Brochard L: Volume-guaranteed pressure-support ventilation facing acute changes in ventilatory demand. Intensive Care Med 2005; 31:1181-8

4. Jaber S, Sebbane M, Verzilli D, Matecki S, Wysocki M, Eledjam JJ, Brochard L: Adaptive support and pressure support ventilation behavior in response to increased ventilatory demand. ANESTHESIOLOGY 2009; 110:620-7

5. Ranieri VM, Grasso S, Mascia L, Martino S, Fiore T, Brienza A, Giuliani R: Effects of proportional assist ventilation on inspiratory muscle effort in patients with chronic obstructive pulmonary disease and acute respiratory failure. ANESTHESIOLOGY 1997; 86:79-91

6. Thille AW, Cabello B, Galia F, Lyazidi A, Brochard L: Reduction of patient-ventilator asynchrony by reducing tidal volume during pressure-support ventilation. Intensive Care Med 2008; 34:1477-86

7. Gama de Abreu M, Spieth PM, Pelosi P, Carvalho AR, Walter C, Schreiber-Ferstl A, Aikele P, Neykova B, Hubler M, Koch T: Noisy pressure support ventilation: A pilot study on a new assisted ventilation mode in experimental lung injury. Crit Care Med 2008; 36:818-27

8. Spieth PM, Carvalho AR, Güldner A, Pelosi P, Kirichuk O, Koch T, de Abreu MG: Effects of different levels of pressure support variability in experimental lung injury. ANESTHESIOLOGY 2009; 110:342-50
9. Burns KE, Lellouche F, Lessard MR: Automating the weaning process with advanced closed-loop systems. Intensive Care Med 2008; 34:1757-65

10. Lellouche F, Brochard L: Advanced closed loops during mechanical ventilation (PAV, NAVA, ASV, SmartCare). Best Pract Res Clin Anaesthesiol 2009; 23:81-93

11. Arnal JM, Wysocki M, Nafati C, Donati S, Granier I, Corno G, Durand-Gasselin J: Automatic selection of breathing pattern using adaptive support ventilation. Intensive Care Med 2008 34:75-81

12. Gruber PC, Gomersall CD, Leung P, Joynt GM, Ng SK, Ho KM, Underwood MJ: Randomized controlled trial comparing adaptive-support ventilation with pressure-regulated volume-controlled ventilation with automode in weaning patients after cardiac surgery. ANeSTHESIOLOGY 2008; 109:81-7

13. Sulzer CF, Chioléro R, Chassot PG, Mueller XM, Revelly JP: Adaptive support ventilation for fast tracheal extubation after cardiac surgery: A randomized controlled study. ANESTHESIOLOGY 2001; 95:1339-45

14. Lellouche F, Mancebo J, Jolliet P, Roeseler J, Schortgen F, Dojat M, Cabello B, Bouadma L, Rodriguez P, Maggiore S, Reynaert M, Mersmann S, Brochard L: A multicenter randomized trial of computer-driven protocolized weaning from mechanical ventilation. Am J Respir Crit Care Med 2006; 174:894-900

15. Raemer DB, Ji XB, Topulos GP: FIx controller: An instrument to automatically adjust inspired oxygen fraction using feedback control from a pulse oximeter. J Clin Monit 1997; 13:91-101

16. Urschitz MS, Horn W, Seyfang A, Hallenberger A, Herberts T, Miksch S, Popow C, Müller-Hansen I, Poets CF: Automatic control of the inspired oxygen fraction in preterm infants: A randomized crossover trial. Am J Respir Crit Care Med 2004; 170:1095-100

17. Arnal JM, Paquet J, Wysocki M, Demory D, Donati S, Granier I, Corno G, Durand-Gasselin J: Optimal duration of a sustained inflation recruitment maneuver in ARDS patients. Intensive Care Med 2011; 37:1588-94

18. Mutch WA, Eschun GM, Kowalski SE, Graham MR, Girling LG, Lefevre GR: Biologically variable ventilation prevents deterioration of gas exchange during prolonged anaesthesia. Br J Anaesth 2000; 84:197-203

19. Tobin MJ, Mador MJ, Guenther SM, Lodato RF, Sackner MA Variability of resting respiratory drive and timing in healthy subjects. J Appl Physiol 1988; 65:309-17

20. Boutron I, Moher D, Altman DG, Schulz KF, Ravaud P; CONSORT Group: Extending the CONSORT statement to randomized trials of nonpharmacologic treatment: Explanation and elaboration. Ann Intern Med 2008; 148:295-309

21. Bigatello LM, Pesenti A: Ventilator-induced lung injury: Less ventilation, less injury. ANESTHESIOLOGy 2009; 111:699-700

22. Jolliet $\mathrm{P}$, Watremez $\mathrm{C}$, Roeseler J, Ngengiyumva JC, de Kock M, Clerbaux T, Tassaux D, Reynaert M, Detry B, Liistro G Comparative effects of helium-oxygen and external positive end-expiratory pressure on respiratory mechanics, gas exchange, and ventilation-perfusion relationships in mechanically ventilated patients with chronic obstructive pulmonary disease. Intensive Care Med 2003; 29:1442-50

23. Wysocki M, Arnal J, Feissel M, l'Her E, Roeseler J, Lellouche F: What ventilation and blood gases are "desirable" in adult mechanically ventilated patients. Intensive care medicine 2010; Abstract 136

24. Laubscher TP, Heinrichs W, Weiler N, Hartmann G, Brunner JX: An adaptive lung ventilation controller. IEEE Trans Biomed Eng 1994; 41:51-9

25. Jung B, Constantin JM, Rossel N, Le Goff C, Sebbane M, Coisel Y, Chanques G, Futier E, Hugon G, Capdevila X, Petrof B, Matecki S, Jaber S: Adaptive support ventilation prevents ventilator-induced diaphragmatic dysfunction in 
piglet: An in vivo and in vitro study. AnESTHESIOLOGy 2010; 112:1435-43

26. Tassaux D, Dalmas E, Gratadour P, Jolliet P: Patient-ventilator interactions during partial ventilatory support: A preliminary study comparing the effects of adaptive support ventilation with synchronized intermittent mandatory ventilation plus inspiratory pressure support. Crit Care Med 2002; 30:801-7

27. ARDS-Network: Ventilation with lower tidal volumes as compared with traditional tidal volumes for acute lung injury and the acute respiratory distress syndrome. The ARDS network. N Engl J Med 2000; 342:1301-8

28. Dojat M, Harf A, Touchard D, Lemaire F, BrochardV L: Clinical evaluation of a computer-controlled pressure support mode. Am J Respir Crit Care Med 2000; 161(4 Pt 1):1161-6

29. Chanques G, Payen JF, Mercier G, de Lattre S, Viel E, Jung B, Cissé M, Lefrant JY, Jaber S: Assessing pain in non-intubated critically ill patients unable to self report: An adaptation of the Behavioral Pain Scale. Intensive Care Med 2009; 35:2060-7

30. Chanques G, Sebbane M, Barbotte E, Viel E, Eledjam JJ, Jaber $S$ : A prospective study of pain at rest: Incidence and characteristics of an unrecognized symptom in surgical and trauma versus medical intensive care unit patients. ANESTHESIOLOGY 2007; 107:858-60

31. Jaber S, Sebbane M, Koechlin C, Hayot M, Capdevila X, Eledjam JJ, Prefaut C, Ramonatxo M, Matecki S: Effects of short $v s$. prolonged mechanical ventilation on antioxidant systems in piglet diaphragm. Intensive Care Med 2005; 31:1427-33

32. Wysocki M, Cracco C, Teixeira A, Mercat A, Diehl JL, Lefort Y, Derenne JP, Similowski T: Reduced breathing variability as a predictor of unsuccessful patient separation from mechanical ventilation. Crit Care Med 2006; 34:2076-83

33. Sydow M, Burchardi H, Ephraim E, Zielmann S, Crozier TA: Long-term effects of two different ventilatory modes on oxygenation in acute lung injury. Comparison of airway pressure release ventilation and volume-controlled inverse ratio ventilation. Am J Respir Crit Care Med 1994; 149:1550-6

34. Brewster JF, Graham MR, Mutch WA: Convexity, Jensen's inequality and benefits of noisy mechanical ventilation. $\mathrm{J} R$ Soc Interface 2005; 2:393-6

35. Suki B, Alencar AM, Sujeer MK, Lutchen KR, Collins JJ, Andrade JS Jr, Ingenito EP, Zapperi S, Stanley HE: Lifesupport system benefits from noise. Nature 1998; 393:127-8

36. Ma B, Suki B, Bates JH: Effects of recruitment/derecruitment dynamics on the efficacy of variable ventilation. J Appl Physiol 2011; 110:1319-26

37. Arold SP, Suki B, Alencar AM, Lutchen KR, Ingenito EP Variable ventilation induces endogenous surfactant release in normal guinea pigs. Am J Physiol Lung Cell Mol Physiol 2003; 285:L370-5

38. Carvalho AR, Spieth PM, Pelosi P, Beda A, Lopes AJ, Neykova B, Heller AR, Koch T, Gama de Abreu M: Pressure support ventilation and biphasic positive airway pressure improve oxygenation by redistribution of pulmonary blood flow. Anesth Analg 2009; 109:856-65

39. Arnal JM, Wysocki M, Novotni D, Demory D, Lopez R, Donati S, Granier I, Corno G, Durand-Gasselin J: Safety and efficacy of a fully closed-loop control ventilation (IntelliVent-ASV) in ICU patients: A prospective randomized cross-over study. Intensive Care Med 2012; 38:781-7

40. Lellouche F, Bouchard P, Laubscher T, Blackburn S, L'Her E, Wysocki M: Prospective randomized controlled study comparing conventional ventilation versus a fully closed-loop ventilation (IntelliVent ${ }^{\circledR}$ ) in post cardiac surgery ICU patients. Intensive care medicine 2010; Abstract 36

41. Brower RG, Lanken PN, MacIntyre N, Matthay MA, Morris A Ancukiewicz M, Schoenfeld D, Thompson BT; National Heart, Lung, and Blood Institute ARDS Clinical Trials Network: Higher versus lower positive end-expiratory pressures in patients with the acute respiratory distress syndrome. N Engl J Med 2004; 351:327-36 